\title{
Alex Loayza (editor). La independencia peruana como representación. Historiografía, conmemoración y escultura pública. Lima: Instituto de Estudios Peruanos, 2016.
}

DOI: http://dx.doi.org/10.15648/hc.31.2017.12

En el contexto de los bicentenarios de las independencias de los países de América Latina y la eclosión de diversos eventos y publicaciones, fue realmente un privilegio y una satisfacción participar en el VII Congreso Nacional de Historia del Perú realizado en la Universidad Nacional de Trujillo en donde tuvo lugar la presentación precisamente del reciente libro La independencia peruana como representación editado por el colega e historiador peruano Alex Loayza, docente de la Universidad San Ignacio de Loyola y exdirector del Seminario de Historia Rural Andina de la Universidad Nacional Mayor de San Marcos (2016). Privilegio porque asistimos a una reunión académica sobre la independencia en el Perú la el cual el libro de Alex Loayza fue el pretexto propicio para un debate mayor en donde la historiadora peruana residente en Estados Unidos Cecilia Méndez y el historiador español Manuel Chuts intercambiaron argumentos provocadores tanto con el editor como con los diez autores de los artículos publicados en el libro.

La premisa clave de aquel debate estuvo circunscrito a una nueva lectura de un proceso histórico que hoy, a casi doscientos años de producido, originó un conjunto amplio de cambios y a la vez de permanencias en el imaginario político y cultural del país. Como indicó en 1972 el historiador Heraclio Bonilla, quizás sea la independencia la etapa de nuestra historia que más ha merecido las portadas de las noticias, pero que a la vez repre- 
senta un capítulo aún no concluido y hasta oscuro de la historia nacional. En ese sentido, volver a repensar estos temas resulta, a puertas del bicentenario, una excelente oportunidad para poner en la agenda del debate y la investigación esta etapa fundacional de la historia del Perú que Jorge Basadre denominó la promesa de la vida peruana.

La independencia peruana como representación de Alex Loayza toca un punto crucial en la historia de los desencuentros de la historia del Perú y avizora a su vez un nuevo panorama en la construcción de la nueva república: lo que Basadre insistió en sostener el Perú como problema y además como posibilidad. Efectivamente, la introducción y los diez capítulos del libro muestran esa otra lectura; una mirada distinta de un mismo proceso histórico que tantos textos, artículos e investigaciones han producido, desde el mismo día de la independencia, hasta ahora en los albores del bicentenario. Los textos compilados por Loayza y publicados por el Instituto de Estudios Peruanos muestran en general tres aspectos novedosos de análisis: el mundo de la historiografía pensada en su contexto, autores y problemáticas, las efemérides de las conmemoraciones especialmente de los centenarios, además del poder y el uso político del estudio de las esculturas públicas en un escenario de cambios y transformaciones sociales del país. Realmente, este texto no es una publicación más en la inveterada producción académica peruana y latinoamericana, sino, por el contrario, se inscribe en una nueva línea de reflexión teórica y problematizadora de la independencia. Esta novedad en la investigación y nueva propuesta historiográfica no es ajena a un debate más amplio sostenido por historiadores y científicos sociales de otras latitudes, porque actualmente las guerras de independencia, consideradas por muchos de nosotros, no pueden entenderse a partir de un estudio focalizado en los espacios regionales y nacionales, deben ir de la mano de una discusión mayor: la de la independencia de América. Por ello, los artículos que componen el libro de Alex Loayza se nutren de diversas vertientes historiográficas que van desde la historia social, política, cultural, historia del arte y de los espacios públicos hasta la historia como representación, al estilo de Roger Chartier.

La primera parte del texto es una muestra clara de esta nueva manera de repensar la independencia a partir de un balance inteligente de la histo- 
riografía y su tiempo. Mientras Loayza reconstruye ese mundo intrincado de los historiadores y sus discursos históricos, Juan Fonseca ensaya una aproximación a dicha historiografía, pero enfocada en las guerrillas y la dinámica popular con ciertas evidencias empíricas. En otras palabras, el análisis parte de un examen minucioso de la producción histórica de los paradigmas de la historia y los historiadores de la independencia, pero a partir de un estudio que se orienta en los problemas de esta historiografía, el contexto en el cual se desarrollaron, las influencias externas e internas que tuvieron, así como en los aportes y las debilidades que sostienen. Una historia de los historiadores y sus discursos históricos explorados en el tiempo y desde sus propias perspectivas, todo ello es clave si, comúnmente olvidados reflexionar sobre nuestra propia ciencia, y aún en una etapa realmente compleja y problemática como la de la independencia.

La segunda parte del libro editado por Loayza retoma una temática que en la historiografía de América Latina viene siendo examinada como parte de las efemérides de los bicentenarios. Pero en el caso concreto del Perú se concentra en los centenarios de la independencia y las representaciones que se construyeron en diversos pueblos y provincias del país. Pablo Ortemberg se concentra en Lima y los acaecimientos conmemorativos de 1921 y 1924 estableciendo una relación compartida de experiencia y política regional donde el oncenio de Leguía juega un rol importante, Guillermo Marín viaja metafóricamente al sur rebelde de la ciudad de Arequipa en dicho contexto festivo y Carlota Casalino rehace argumentos de la comunidad de cultos y la construcción de los héroes a partir de la figura de Francisco de Zela y la rebelión de Tacna entre 1811 y 1911. En esa misma línea de indagación, Carlos Hurtado Ames desarrolla la conmemoración del centenario de la independencia en un interesante pero confuso espacio local: el de la ciudad de Jauja, mientras que Iván Caro realiza una pedagogía de análisis sosteniendo a la historia como pretexto para comprender las relaciones del pasado y el presente en la coyuntura de la celebración del centenario de 1924 en Ayacucho. En esencia, las representaciones que podemos advertir en todos estos espacios regionales y en la misma capital con motivo de los centenarios arrojan una serie de argumentos en donde el pasado siempre está presente en la vida de las personas y las celebraciones son el fiel reflejo de esas realidades y, además, de los cambios y las 
reconstrucciones de una legitimidad política enclaustrada en la memoria colectiva de nuestro país.

Finalmente, la tercera parte de La independencia como representación se interesa en el desarrollo de la escultura pública conmemorativa pensándola como una herramienta sugerente para un estudio no solamente de historia del arte o de la escultura en el Perú, sino concentrándose en la parte social y política de aquella, en otras palabras, el uso político y las relaciones sociales que se vislumbran en una temática que va más allá de un examen de cosas muertas o monumentos sin sentido ni capacidad de representación. Por el contrario, los trabajos de Nanda Leonardini, Daniel Vifian y Rodolfo Monteverde cruzan esa frontera limítrofe y asfixiante de la historia tradicional para proponer una forma diferente de entender las conmemoraciones a partir de sus restos y sus testimonios. Solo así comprendemos la relación entre escultura e independencia en el Ayacucho de su tiempo, el pasado y el nuestro que estudia Leonardini, o quizás el civismo, la ciudadanía y la construcción de los héroes plasmados en monumentos como lo desarrollan eficientemente Vifian para el caso de Bolívar en Lima, y Monteverde y el libertador San Martín entre la república aristocrática y el oncenio de Leguía.

Evidentemente, estos tres nuevos aspectos en la investigación del proceso de la independencia que son trabajados en el libro editado por Alex Loayza muestran una variante mucho más rica en los estudios de esta etapa de la revolución y guerra en el Perú y América, que comúnmente no se observa en otras publicaciones de la misma temática. Entonces, La independencia como representación es precisamente ello: una reconstrucción a partir de los discursos, las experiencias, las conmemoraciones y los monumentos que son pensados como parte de un péndulo que va del pasado al presente y hacia el porvenir de nuestro país. El bicentenario de la independencia es el pretexto para seguir ensayando estos tipos de investigaciones y apostar por algo atrayente, pero con base en un conjunto diverso de fuentes y evidencias que rompan con el paradigma de la historia tradicional. Cómo sostuvo Peter Burke todo es fuente para el conocimiento histórico: sea un escrito, un poema, una comunicación oral, una escultura, una fotografía, etc., mientras nos permita reconstruir la historia del hombre en sociedad. 
El texto La independencia como representación si bien cubre muchos temas de la realidad de este proceso histórico deja abierta también la posibilidad de replantear estas premisas y reorganizarlas en una perspectiva de largo aliento que priorice las relaciones sociales y los intereses políticos de todos los actores que forman parte de esta gesta independentista, que buscaría en poco tiempo, proponer una mirada más consistente de la independencia y sus representaciones.

Daniel Morán

Universidad San Ignacio de Loyola, Lima-Perú. danielmoran2009@gmail.com 